\title{
AN INTER-INDUSTRY COMPARISON OF INVENTORY MANAGEMENT AGAINST DISASTER RISKS: EVIDENCE FROM JAPAN
}

\author{
Shinnosuke Hara \\ Nagoya University of Foreign Studies, Japan \\ E-mail: haras@nufs.ac.jp
}

\begin{abstract}
Measures against disasters such as earthquakes are one of the most important tasks of companies all over the world. Especially in cases of the Tohoku Earthquake and Tsunami of 2011 and the Kumamoto Earthquake of 2016, factories producing high specificity parts suffered severe damage, as they could no longer supply final products. The occurrence of natural disasters is an interruption in the supply chain. Some studies on accidental or exceptional events such as natural disasters have finally come about after the Tohoku Earthquake. Recently, the effectiveness and necessity of management accounting have been pointed out from the perspective of providing information for formulating and updating business continuity plans in the context of reconstruction after disasters and returning to normalcy. While accounting research is relatively lacking, research on handling of risks due to disasters from a similar problem such as implementation of inventory management can be seen in different fields. In this paper we review not only accounting but interdisciplinary research, and focus on topics of inventory management and lean production methods that have similarities with management accounting research. A low inventory level associated with lean production can lead to increased vulnerability to disasters. To investigate implementation of inventory management in companies, we quantitatively analyzed time series trends of inventory and identified the industry in which features of an increase or decrease are seen.
\end{abstract}

Keywords: inventory, time series analysis, disaster, risk, supply chain

\section{$\underline{\text { ARTICLE INFO }}$}

\section{Article History:}

Received: 19 October 2019

Accepted: 9 January 2020

Published: 30 April 2020 


\section{INTRODUCTION}

In recent years, damage to companies due to sudden natural disasters has been drawing considerable attention in Japan. Especially in cases of the Tohoku Earthquake and Tsunami of 2011 and the Kumamoto Earthquake of 2016, factories producing highly specialized parts such as microcomputers suffered severe damage, and could no longer supply final products. The occurrence of natural disasters is an interruption in the supply chain.

Such circumstances are often expressed by the word "risk." However, risks in management accounting research are recognized as possible uncertainties or variations in executing businesses and strategies. These risks are relatively predictable or estimable. On the other hand, studies on accidental or exceptional events such as natural disasters have finally come about after the Tohoku Earthquake. Recently, the effectiveness and necessity of management accounting has been pointed out from the perspective of providing information for formulating and updating business continuity plans (BCPs) in the context of reconstruction after disasters and returning to normalcy (Sasaki, 2012; Okazaki, 2016).

While accounting research is largely lacking, research on handling the risks of disasters from a similar problem such as implementation of inventory management can be seen in different fields, especially logistics management and production management in supply chain management. And some of them suggest that when considering such risks, a different business management policy may be adopted (Park et al., 2012; Baroud et al., 2016). With this in mind, we reviewed not only accounting but interdisciplinary research, and focused on topics of inventory management and lean production methods that have similarities with management accounting research. Subsequently, we quantitatively analyzed time series trends of inventory and identified the industries in which these features are seen.

The structure of this paper is as follows. In the next section, we will present and organize the trends related to disaster risk management with a focus on inventory management. In Section 3, we analyze the inventory turnover period by industry. In Section 4, we examine the results of our analysis, and in Section 5, we conclude the paper and offer directions for future research. 


\section{LITERATURE REVIEW}

\section{Inventory Management at Normal Times}

Prior to the discussion on inventory management, we summarize the necessity for an inventory. In accounting, the inventory asset is recorded in an accounting form, such as raw materials, work-in-progress, and products, depending on its actual form. In the financial statements, these are sometimes expressed as inventory as a whole, but, it is necessary to grasp how much they are individually, in the managing inventory. However, there is no optimal solution for these ratios and quantities, but, we have to flexibly respond to the environment surrounding the company.

Why do companies own an inventory in the first place? In Simchi-Levi et al. (2000), the following three points were presented. The first reason is as a response to demand fluctuations. For customers, demand always changes, and in today's scenario, with the diversification in products, even though we can predict the demand for the entire product group, it is difficult to accurately estimate individual product demand. The second reason is a response to uncertainty in procurement. The quantity and quality of procurement items, the costs of suppliers, the delivery date, etc., are not necessarily the same each time even in the ordering of the same thing from the same trader. The third reason is pursuit of economies of scale. Ordering the same products in large quantities leads to discounts per unit and reduction in transportation costs, and as a result, companies will have cheaper inventory. Failure to control inventory under these circumstances, will lead to the continued increase in quantity, pressing down on funds and profits.

The main points of inventory control are summarized in the forecast of demand and the calculation of order volume. Demand forecasting is not easy, but it is possible to estimate it using information from the past. However, even if demand can be predicted, the order quantity is not determined uniquely. In the Economic Order Quantity (EOQ) Model, which is widely known as a classic model, assuming the situation of a single variety, constant demand, and single warehouse, we calculate the order quantity that minimizes the sum of ordering and storage costs. It abstracts several events such as variations in delivery lead time (Simchi-Levi et al., 2000). 
In recent years, considerable importance has been placed on the turnover rate or the turnover period of the stock, rather than on the amount of the inventory cost as a method for measuring the quality of inventory management. Reduction in the inventory level is not realized by the decision-making of one enterprise. Cooperation in the supply chain is necessary. Buyers are located downstream of the supply chain and are in a position to make it relatively easy to predict customer demand. Due to the Bullwhip effect, fluctuations in demand become more significant as one goes upstream in the supply chain, making prediction difficult, while suppliers have more accurate information on parts production capacity and lead time than buyers. Although asymmetry of information can cause both sides to indulge in opportunistic behavior, it is necessary to share information with each other in terms of lowering inventory levels (Lee et al., 1997; 2004).

Inventory management methods in the supply chain include quick response strategies (buyer places order, supplier obtains POS information from buyer and uses it for prediction and plan improvement), continuous replenishment strategies (suppliers receiving POS information replenish inventory to maintain a certain level), and vendor managed inventory (VMI). VMI is a management method for suppliers to determine the appropriate stock for each product and to decide the policy for maintaining $\mathrm{it}^{1}$. Many researchers have considered the benefits that VMI provides for the supply chain under various conditions (Nagarajan \& Rajagopalan, 2008; Guan \& Zhao, 2010; Lee et al., 2016). However, some of those studies have been presented on the premise that suppliers act on minimizing the entire cost even if the costs incurred by them increases, that is, it has been pointed out that there may be undesirable results for individual suppliers and buyers (Darwish \& Goyal, 2011).

\section{Inventory Management for Risk}

\section{Research before the Tohoku Earthquake and Tsunami of 2011}

The above-mentioned inventory control method is mainly aimed at reducing demand fluctuations in normal times. As a whole, inventory management is aimed at lower inventory levels, that is, inventory reduction.

1 VMI was a policy that began between $P \& G$ and Walmart in 1985. Under the circumstances where buyer's stock information and demand forecast information can be obtained, it is very effective against the reduction of the Bullwhip effect. As a result, the improvement of service quality, cost reduction, reduction of safety inventory level, etc. can be expected. 
On the other hand, if an event such as an accident or a disaster occurs, fluctuations in supply and demand will exceed the forecasted range, leading to suspension of product supply due to the lack of inventory. These indications were scattered before the Tohoku Earthquake.

Kawakami (2000) showed that in companies that engaged in Just in Time (JIT) production, there was anxiety about not having insurable inventory. As for the relationship between such unexpected risks and inventory, there were some opinions in the field of production control to accept an increasing inventory.

Especially in the context of foreign studies, the importance of BCPs has been pointed out since the September 11 attacks in the United States, and research that refers to inventory control in that context comes up often. Kleindorfer and Saad (2005) listed the ten principles of risk correspondence in the supply chain. They pointed out that promoting extreme lean production and efficiency principle among them led to increased vulnerability both in individual companies and at the supply chain levels. In preparation for this, they said that slack was necessary within a reasonable range. Similarly, from the viewpoint of risk management on the supply chain, Waters (2007) pointed out that the reduction of safety inventory was vulnerable to unexpected events and there was a danger of a business outage. The study also showed that there was a possibility of avoiding it by holding a raw material inventory, product inventory, and work-in-process inventory for risks attributable to suppliers, risk of demand fluctuation, and business risk, respectively. However, most companies around the world tend to carry out lean operations stating that the current situation requires the reduction of the safety stock level mainly for cost reasons.

Besides this, it is pointed out that reducing inventory is not always disadvantageous in terms of risk management. In other words, by constructing a lean supply chain with little inventory, it becomes possible to clarify the problem and to respond promptly, since it makes clear exactly where the inventory stagnated, even in the event of a disaster (Nakamoto, 2007). This can be considered as the same idea as Jidoka or automation in the Toyota Production System. Christopher and Lee (2004) pointed out that the lack of visibility and reliability of problems due to inventory holding leads to the possession of additional safety stock, which also undermines visibility and reliability, and thereafter, leads to a vicious cycle. 
In this way, studies that pointed out the risks of excessive inventory reduction in research up to the 2000 s were found here and there. In addition, it is still necessary to promote inventory reduction while recognizing the existence of risks. However, most of the risks assumed are daily fluctuations and uncertainties, and long-term damage due to large-scale natural disasters is not sufficiently considered.

\section{Research after the Tohoku Earthquake and Tsunami of 2011}

After the Tohoku Earthquake and Tsunami of March 2011, research on inventory management considering large-scale disasters became very common. Immediately after the earthquake, there were some studies asking whether to add inventory in preparation for disasters, mainly from researchers in Japan.

In Fujimoto (2011, 2012), a negative opinion was presented saying that increasing inventory in preparation for an event that is difficult to predict, like a disaster, is not reasonable, because it leads to an increase in cost and the extension of lead time in the long term. It also stated that even if specific suppliers possess a lot of inventory and can cope with disasters, it is useless from the supply chain perspective. The reason was that even if only one supplier suffered from disaster and stopped supply, and one of the parts could not be obtained, then, the product would not be completed. Instead, it proposed "the virtual dualization of the supply chain," which meant, to prepare product design information and multiple production lines that can be switched immediately, at the time of an emergency. Monden (2011) also presented a similar argument that multiple paths for parts procurement and networking of supply chains will be effective as measures against earthquakes.

Matsuo (2015) presented a case study of Toyota, which was building a Just-in-Time mechanism. The study pointed out that the Toyota Group had the ability to recover rapidly from disruption with the cooperation of the supplier network, as shown in the cases of Aisin Seiki's Kariya plant accident in 1997, and the Riken's Kashiwazaki plant which suffered as a result of the Niigataken Chuetsu-oki Earthquake in 2007. In other words, the Japanese automotive supply chain has a feature of high efficiency and its infrastructure is well developed. Therefore, there was no need to increase inventory. 
Ono et al. (2015a, 2015b), which quantitatively analyzed the impact on production in the automobile industry, modeled trends in the level of automobile production before and after a disaster, and simulated how the trend in the production volume changed while implementing vulnerability remediation measures in the supply chain. The speed of production recovery in case of increasing inventory as part of simulation was also studied. Although the studies showed that the speed level of recovery improved in the month following the occurrence of a disaster, it was not possible to obtain the effect of an additional increase after the second month. The studies concluded that increasing inventory was not a very efficient strategy considering the burden on the business.

On the other hand, there is positive research on inventory buildup. Kawano (2012), focused on the automobile industry where one of the biggest impacts of the Tohoku Earthquake was felt. It looked at how the industry considered the situation of damage and risk response immediately after the disaster. For the examination of the situation of damage, inventory turnover ratios ${ }^{2}$ of seven key companies ${ }^{3}$ were calculated for the preceding four years, for the purpose of comparing the inventory situation among finished vehicle manufacturers and groups.

Looking at the turnover ratio, Toyota showed higher values than other companies, followed by Mazda. Based on this result and domestic production situation of each company in June of 2011, it showed: 1) Toyota was influenced far more than Mazda was, due to its size, 2) Honda also delayed recovery from low inventory levels, 3) Nissan and Mitsubishi smoothly restored production capacity after the disaster due to the large number of stocks. In terms of maintaining and recovering production capacity during and after disasters, it concluded that the inventory amount may be the dominant factor in the short term.

In addition, Kawano (2012) pointed out that stopping product supply for a certain period of time may lead to losing market share by not possessing safety stock considering a disaster. In other words, low inventory levels

2 Turnover calculated as follows: Total sales / \{ (Inventory at the end of previous period + Inventory at the end of fiscal year) $/ 2\}$

3 These are Toyota Motor Corporation, Nissan Motor Co., Ltd., Honda Motor Co., Ltd., Fuji Heavy Industries Ltd. (now Subaru Corporation), Mazda Motor Corporation, Mitsubishi Motors Corporation, Suzuki Motor Corporation, and Daihatsu Motor Co., Ltd. 
would lead to lost sales opportunities and eventually customer losses, alleging that it is difficult to recover customers who have gone away once. Therefore, a company should have a certain amount of inventory of finished goods. Similarly, Mackenzie et al. (2012) also found that it was difficult to avoid a decline in production immediately after an incident, but, since a company can satisfy the most recent demand by holding onto an inventory of finished products, it can be expected to increase production thereafter.

As mentioned above, many theoretical arguments and recommendations emerged immediately after the earthquake, but around 2014, there was a survey on the actual situation of companies as regards disaster response, including inventory management, mainly for researchers in supply chain management and logistics fields. Osada and Yano (2014) conducted a questionnaire survey on procurement in logistics, countermeasures in production aspects, and change in thinking on logistics in partly listed companies. They found that $22.6 \%$ companies carried out inventory additions as part of their logistics activities. In addition, they also indicated that some companies converted outsourced production into in-house production, and focused on the ease of restoration from a disaster by looking into production capacity.

Baroud et al. (2016) conducted an interview survey on 42 items that could be considered as measures to deal with risks in the supply chain, and derived those that the companies recognized as valid by the Bayesian estimation. The study pointed out the importance of seven items, including the examination of safety inventory and expansion of the inventory cushion. On the other hand, it showed that there was no big difference in the results depending on the type of industry and the size of the company in question.

In Hara (2016), inventory turnover rates of 11 companies in the Toyota Group from the fiscal year 2008 to 2014, were analyzed on a quarterly basis. Some companies had added inventory after the earthquake, even though they had to promote the Toyota production method. 
Akikawa (2017) conducted a questionnaire survey on the level of implementation of BCPs for food manufacturers. Of the total, $32 \%$ of the companies had formulated BCPs. Whereas the implementation rates of large enterprises in metropolitan areas and companies in Shikoku were high, the implementation rate of rural areas including Tohoku was low. According to the responses received to the additional questions for firms with experience in formulating, $21 \%$ said that their inventory of finished goods had been added up, and $30 \%$ of the companies added the stock of raw material. At the same time, the following three points were cited as characteristics of BCPs for the supply chain, rather than for individual companies: 1) continuity, so that the entire chain stops when a part of the chain ceases, 2) openness, so that it is not completed as one story or one organization and it is easily affected by external factors, 3 ) multifunction, so that companies participate in diverse activities such as procurement, manufacturing, logistics, and information processing.

There are also case studies that focus on the efforts of individual companies. Park et al. (2012) investigated four Japanese manufacturing companies in the fields of medical equipment, construction machinery, industrial machinery, and heavy electric machinery, to examine their responses to earthquakes and tsunamis. Among them, industrial machinery manufacturers showed that they were maintaining inventory for one month longer than the conventional level, with the aim of recovering from the disruption of logistics in the supply chain at the earliest. Similarly, Oura (2015) discussed Omron Corporation to evaluate their procurement risk and organizational design to see if it was effective for risks. The company had been evaluating procurement risks for each part since the earthquake, and positioned parts that were expected to be missing for a relatively long period of time. That had a large company-wide impact, with these parts being considered critical. Usually, they ordered "real orders" " for one month, but made real orders for critical parts for half a year.

4 Omron's course of action was the designation of an ordering method for presenting a predetermined necessary amount to a supplier beforehand, and seeking a reliable delivery date in response to this. Omron would bear the inventory risk on the required amount presented. 


\section{ANALYSIS BASED ON THE AVERAGE AGE OF INVENTORY}

\section{Sample and Research Method}

As a result of the review conducted in the previous section, it is clear that there are a certain number of companies and industries in which there is a change in implementation of inventory management as a result of the Tohoku Earthquake. However, the reasons, causes, and intentions are not shown sufficiently. Concrete examples are accumulated by case studies, but they are not exhaustive. Therefore, in this section, we identify a distinctive industry on the transition of inventory and conduct a comprehensive analysis of the average age of inventory, covering as many industries as possible, with the aim of narrowing down industries presumed to be appropriate as the qualitative survey target.

For the data to be analyzed, we referred to the "Handbook of Industrial Financial Data 2017" edited by Development Bank of Japan, and extracted the value of the average age of inventory (inventories to monthly sales) in the preceding ten years. Among the 1,849 listed companies ${ }^{5}$ for consolidated accounting data, we referred to the data of 1,002 manufacturing companies (17 in middle classification, 58 in small classification). For industries classified as non-manufacturing ones, the absolute amount of inventory was very small, so it was excluded from the analysis.

First, we plotted the average age of inventory for the next 10 years, based on the value of 2006. Next, logarithmic transformation was performed to stabilize the dispersion of the data. Since financial data has heteroscedasticity, it aims to stabilize dispersion by decreasing the range of fluctuation. Finally, in order to verify the time series characteristics, we tested whether the data obeyed the normal distribution by the Shapiro-Wilk test and verified that the data was not an independent sample by WaldWolfowitz (Runs) tests. For the analysis, R (version 3.5.0) was used.

Figure 1 shows the transition of the average age of inventory for 16 industries based on the medium classification, except Miscellaneous Manufacturing. The horizontal axis shows each year, and the vertical axis

5 Company listed on the first or second sections of the Tokyo or Nagoya stock exchange. 
shows the value for each year when the value for fiscal year 2006 was 100 . Figure 2 shows the trends by industry after standardization was performed. Figure 2 shows whether it is increasing or decreasing when compared to the previous year. If it is above the broken line, the value increases when compared to the previous year, and if it is below the broken line it means that the value decreases when compared with the previous year.

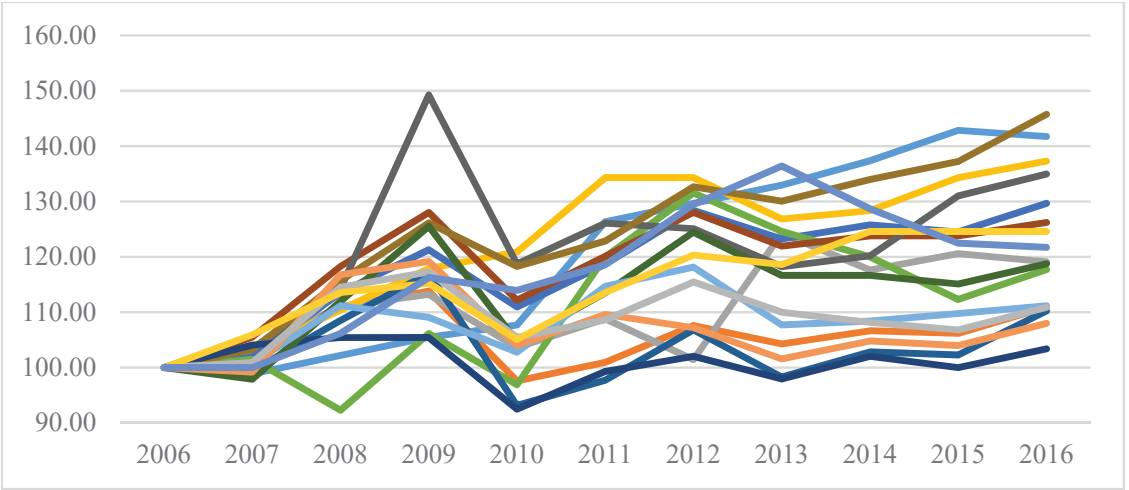

Figure 1: Average Age of Inventory for 16 Industries 


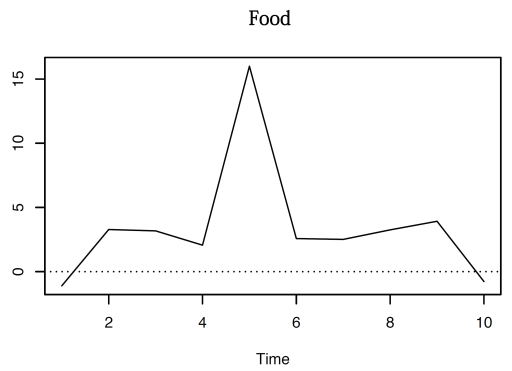

Paper and Pulp

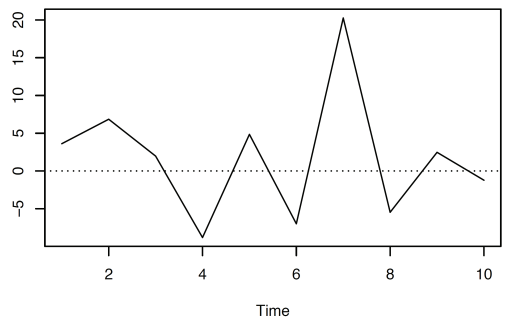

Chemicals

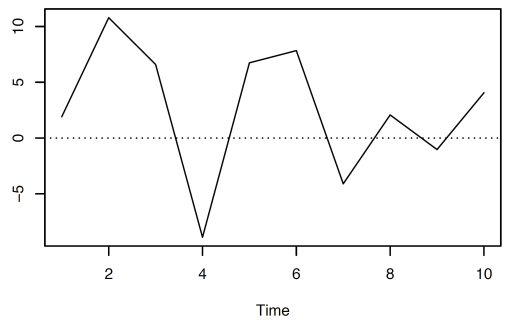

Rubber Pds.

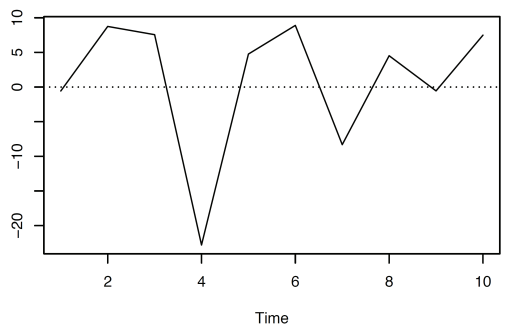

Textiles

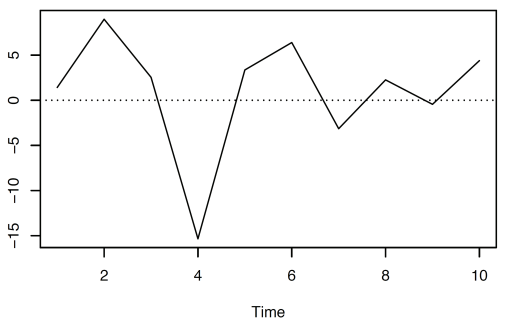

Printing

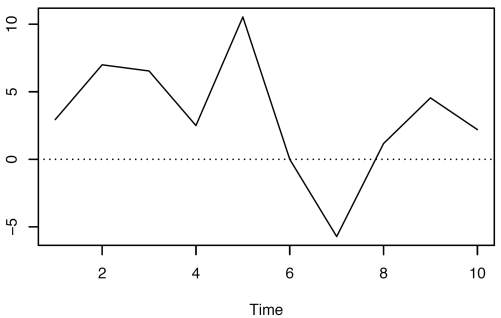

Petroleum

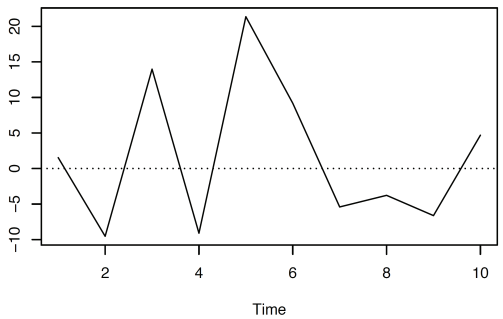

Stone, Clay and Glass Pds.

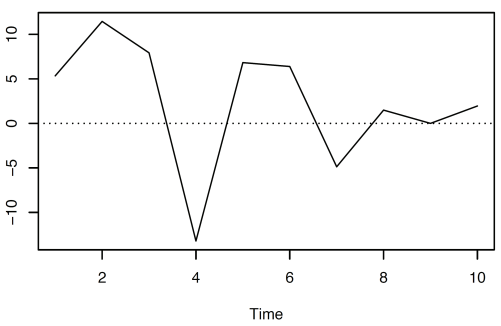


Iron and Steel

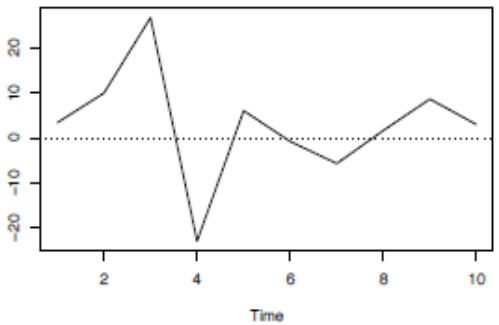

Fabricated Metal Pds.

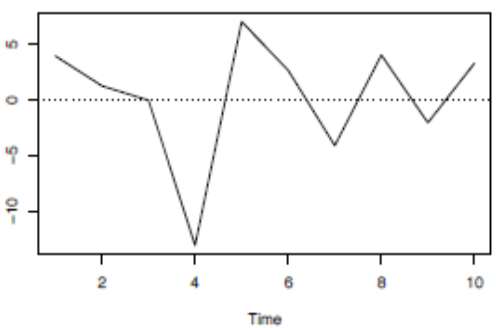

Electric Eq.

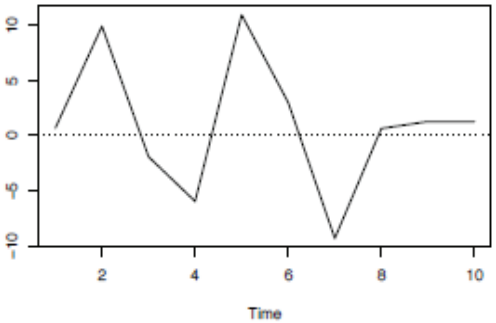

Precision Instruments

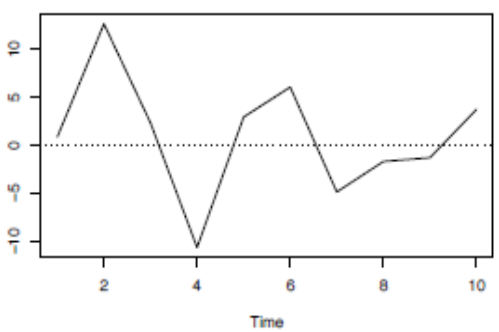

Nongerrous Metals

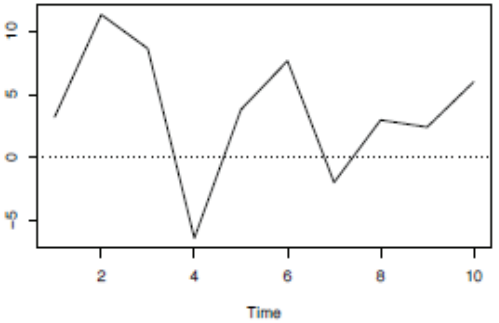

Machinery

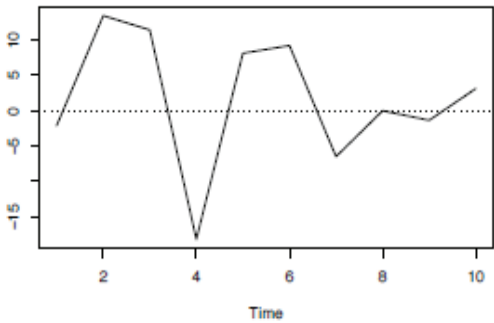

Transportation and Eq.

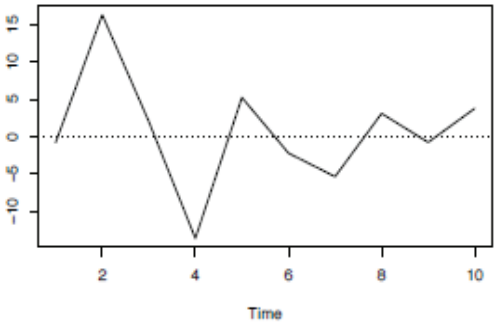

Plastic Pds.

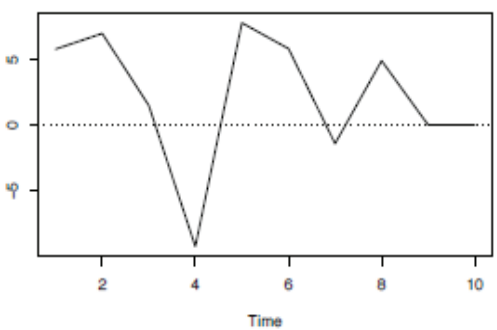

Figure 2: Trends by Industry After Standardization 
From the figures, it seems likely that we can subjectively identify the industry where a certain trend can be seen. Here, we conducted two tests with the aim of seeing those trends more objectively.

\section{Shapiro-Wilk Test}

Here, we tested whether or not the data followed a normal distribution. The null hypothesis was that "the target data follows a normal distribution." While judging with a significance level of $5 \%$, if the p-value exceeded $5 \%$, the null hypothesis was accepted and it was recognized that the target data conformed to the normal distribution.

\section{Wald-Wolfowitz Test}

In this test, the presence or absence of regularity on the arrangement of data was tested. Based on the average value for each industry, we replaced it with binary data that the numerical value of each year exceeded $(+)$ or was less (-) than the average value. The null hypothesis was that there is no regularity in the sequence of "+" and "-". While judging with the significance level 5\%, if the p-value was less than 5\%, the null hypothesis was rejected and it was recognized that there was regularity in the order of "+" and "-".

Tables 1 and 2 show the results of the above two tests for the medium classification of 17 industries and the small classification of 59 industries (** means $\mathrm{p}<0.01 ; *$ means $\mathrm{p}<0.05 ; \uparrow \mathrm{p}<0.1$ ).

Table 1: Statistical Testing for Middle Classification

\begin{tabular}{lccc}
\hline $\begin{array}{c}\text { Industry group } \\
\text { (Middle classification) }\end{array}$ & $\begin{array}{c}\text { Number of } \\
\text { company }\end{array}$ & $\begin{array}{c}\text { Shapiro-Wilk } \\
\text { test }\end{array}$ & $\begin{array}{c}\text { Wald-Wolfowitz } \\
\text { test }\end{array}$ \\
\hline Foods & 89 & $0.0616+$ & $0.0043^{* *}$ \\
Textiles & 35 & 0.8205 & 0.7706 \\
Paper and Pulp & 16 & 0.4877 & 0.1153 \\
Printing & 15 & 0.1601 & $0.0043^{* *}$ \\
Chemicals & 145 & 0.2074 & 0.1474 \\
Petroleum & 7 & 0.7514 & $0.0043^{* *}$
\end{tabular}




\begin{tabular}{lccc}
\hline $\begin{array}{c}\text { Industry group } \\
\text { (Middle classification) }\end{array}$ & $\begin{array}{c}\text { Number of } \\
\text { company }\end{array}$ & $\begin{array}{c}\text { Shapiro-Wilk } \\
\text { test }\end{array}$ & $\begin{array}{c}\text { Wald-Wolfowitz } \\
\text { test }\end{array}$ \\
\hline Rubber Products & 18 & 0.7854 & 0.9498 \\
Stone, Clay and Glass Products. & 42 & $0.0799 \dagger$ & 0.1474 \\
Iron and Steel & 40 & 0.9159 & 0.7706 \\
Nonferrous Metals & 29 & 0.8038 & 0.1153 \\
Fabricated Metal Products & 44 & 0.2731 & 0.3215 \\
Machinery & 139 & 0.4367 & 0.1474 \\
Electric Equipment & 169 & 0.6747 & 0.7706 \\
Transportation and Equipment & 101 & 0.2238 & 0.7706 \\
Precision Instruments & 33 & 0.7865 & 0.7706 \\
Plastic Products & 27 & 0.2694 & 0.1153 \\
Misc. Manufacturing & 53 & 0.6878 & 0.0043 ** \\
\hline
\end{tabular}

Table 2: Statistical Testing for Small Classification

\begin{tabular}{|c|c|c|c|c|}
\hline $\begin{array}{c}\text { Industry group } \\
\text { (Middle classification) }\end{array}$ & $\begin{array}{l}\text { Industry group } \\
\text { (Small classification) }\end{array}$ & $\begin{array}{l}\text { Number of } \\
\text { company }\end{array}$ & $\begin{array}{l}\text { Shapiro-Wilk } \\
\text { test }\end{array}$ & $\begin{array}{c}\text { Wald- } \\
\text { Wolfowitz } \\
\text { test }\end{array}$ \\
\hline \multirow{6}{*}{ Foods } & $\begin{array}{l}\text { Meat and Dairy } \\
\text { Products }\end{array}$ & 12 & 0.7153 & 0.0042 ** \\
\hline & $\begin{array}{l}\text { Grain Milling and } \\
\text { Feeds }\end{array}$ & 9 & $0.0918 \dagger$ & 0.0043 ** \\
\hline & Breweries & 3 & 0.5792 & 0.1474 \\
\hline & Seasonings & 10 & 0.3292 & $0.0043 * *$ \\
\hline & $\begin{array}{l}\text { Confectionery and } \\
\text { Bakery }\end{array}$ & 12 & 0.5163 & 0.1153 \\
\hline & Other Foods & 9 & $0.0041^{* *}$ & $0.0043^{* *}$ \\
\hline \multirow{3}{*}{ Textiles } & Synthetic Fibers & 3 & 0.3230 & 0.9498 \\
\hline & Spinning & 12 & 0.6445 & 0.9498 \\
\hline & Other Textiles & 20 & 0.4018 & 0.0043 ** \\
\hline
\end{tabular}




\begin{tabular}{|c|c|c|c|c|}
\hline $\begin{array}{l}\text { Industry group } \\
\text { (Middle classification) }\end{array}$ & $\begin{array}{c}\text { Industry group } \\
\text { (Small classification) }\end{array}$ & $\begin{array}{l}\text { Number of } \\
\text { company }\end{array}$ & $\begin{array}{c}\text { Shapiro-Wilk } \\
\text { test }\end{array}$ & $\begin{array}{c}\text { Wald- } \\
\text { Wolfowitz } \\
\text { test }\end{array}$ \\
\hline \multirow{7}{*}{ Chemicals } & Chemicals-Major & 6 & 0.7705 & 0.1153 \\
\hline & Organic Chemicals & 27 & 0.1877 & 0.1153 \\
\hline & Inorganic Chemicals & 25 & 0.4446 & 0.9498 \\
\hline & $\begin{array}{l}\text { Oil, Fats and } \\
\text { Cosmetics }\end{array}$ & 17 & 0.3242 & 0.0046 ** \\
\hline & Paints & 17 & 0.8154 & 0.7706 \\
\hline & Pharmaceuticals & 30 & 0.1733 & 0.0043 ** \\
\hline & Other Chemicals & 23 & 0.9034 & 0.3507 \\
\hline \multirow{2}{*}{ Rubber Products } & Tires & 4 & 0.6929 & 0.9498 \\
\hline & Other Rubber Products & 14 & 0.5283 & 0.1474 \\
\hline \multirow{5}{*}{$\begin{array}{l}\text { Stone, Clay and Glass } \\
\text { Products. }\end{array}$} & Cement & 3 & 0.3935 & 0.1153 \\
\hline & Sheet Glass & 3 & 0.0408 * & 0.1153 \\
\hline & $\begin{array}{l}\text { Other Glass and } \\
\text { Glassware }\end{array}$ & 5 & 0.1847 & 0.0043 ** \\
\hline & Ceramic Wares & 7 & $0.0636 \dagger$ & 0.3215 \\
\hline & $\begin{array}{l}\text { Other Stone and Clay } \\
\text { Products }\end{array}$ & 24 & 0.5136 & 0.3507 \\
\hline \multirow{4}{*}{ Iron and Steel } & Iron and Steel-Major & 4 & 0.9017 & 0.7706 \\
\hline & Ordinary Steel & 9 & $0.0509 \dagger$ & 0.1474 \\
\hline & Special Steel & 9 & 0.0098 ** & 0.4497 \\
\hline & Other Steel Products & 9 & $0.0981 \dagger$ & 0.9498 \\
\hline \multirow{4}{*}{ Nonferrous Metals } & $\begin{array}{l}\text { Nonferrous Metal } \\
\text { Refining }\end{array}$ & 13 & 0.7801 & 0.1153 \\
\hline & $\begin{array}{l}\text { Nonferrous Metal } \\
\text { Rolling }\end{array}$ & 3 & $0.0600 \dagger$ & 0.0055 ** \\
\hline & Wire and Cables & 10 & 0.6809 & 0.1474 \\
\hline & Die Castings & 3 & 0.1093 & 0.7264 \\
\hline
\end{tabular}


An Inter-Industry Comparison of Inventory Management Against

\begin{tabular}{|c|c|c|c|c|}
\hline $\begin{array}{l}\text { Industry group } \\
\text { (Middle classification) }\end{array}$ & $\begin{array}{l}\text { Industry group } \\
\text { (Small classification) }\end{array}$ & $\begin{array}{l}\text { Number of } \\
\text { company }\end{array}$ & $\begin{array}{c}\text { Shapiro-Wilk } \\
\text { test }\end{array}$ & $\begin{array}{c}\text { Wald- } \\
\text { Wolfowitz } \\
\text { test }\end{array}$ \\
\hline \multirow{8}{*}{ Machinery } & Machine Tools & 23 & 0.0288 * & 0.7706 \\
\hline & Agricultural Machinery & 4 & 0.9592 & 0.1474 \\
\hline & Construction Machinery & 8 & 0.1394 & 0.1153 \\
\hline & $\begin{array}{l}\text { Chemical Plants and } \\
\text { Tanks }\end{array}$ & 15 & $0.0012^{* *}$ & $0.0055^{* *}$ \\
\hline & Office Machines & 14 & 0.9993 & 0.1153 \\
\hline & Other Machinery & 61 & 0.7486 & 0.4497 \\
\hline & Bearings & 5 & 0.4388 & 0.0267 * \\
\hline & Other Machinery Parts & 9 & 0.0231 * & 0.7706 \\
\hline \multirow{7}{*}{ Electric Equipment } & $\begin{array}{l}\text { Computers and Electric } \\
\text { Eq. }\end{array}$ & 6 & 0.2553 & 0.4497 \\
\hline & Industrial Electric Eq. & 37 & 0.2143 & 0.9498 \\
\hline & Communications Eq. & 24 & 0.6869 & 0.0267 * \\
\hline & $\begin{array}{l}\text { Electric Measuring } \\
\text { Instr. }\end{array}$ & 12 & 0.4435 & 0.7706 \\
\hline & $\begin{array}{l}\text { Electric Eq. and } \\
\text { Components }\end{array}$ & 60 & 0.2481 & $0.0043^{* *}$ \\
\hline & $\begin{array}{l}\text { Household Electric } \\
\text { Appl. }\end{array}$ & 20 & 0.3983 & 0.3507 \\
\hline & Other Electric Eq. & 10 & 0.8395 & 0.7706 \\
\hline \multirow{4}{*}{$\begin{array}{l}\text { Tran s portation } \\
\text { Equipment }\end{array}$} & Automobiles & 9 & 0.6289 & 0.7706 \\
\hline & $\begin{array}{l}\text { Auto Parts and } \\
\text { Accessories }\end{array}$ & 69 & 0.4630 & $0.0043 * *$ \\
\hline & Shipbuilding-Major & 6 & 0.7141 & 0.0267 * \\
\hline & $\begin{array}{l}\text { Other Transportation } \\
\text { Eq. }\end{array}$ & 17 & 0.3603 & 0.1153 \\
\hline \multirow{2}{*}{ Precision Instruments } & Optical Instruments & 7 & 0.7860 & 0.1153 \\
\hline & Other Precision Instr. & 26 & 0.3561 & 0.4497 \\
\hline
\end{tabular}




\section{DISCUSSION}

Industries in which the data followed the normal distribution (not significant in the Shapiro-Wilk test) and in which regularity was seen increasing and decreasing (significant in Wald-Wolfowitz tests) were 13 in all, listed in bold. Besides the food industry that was suggested in past studies, there is an increasing trend in the cosmetics, pharmaceuticals, electrical equipment, and auto parts industries.

Considering the characteristics of these industries from the viewpoint of counterparties, the industry dealing with daily necessities such as food or cosmetics was also the core business of B-to-C, and in these industries, there was increasing inventory in all companies located from the upstream to the downstream in the supply chain. On the other hand, in companies dealing with industrial products such as electronic equipment parts and automobile parts, inventory is increasing in companies upstream of the supply chain, for which the core business is B-to-B, while there is no statistically significant trend in the inventory of companies that manufacture final products, such as industrial electricity equipment, consumer electronics, and the automobile industries.

There are a considerable number of studies on the relationship between the lean production system as represented by JIT and management accounting, including the influence on cost. However, the main target is located at the most downstream point in the supply chain, such as final product manufacturers, who were often subject to research. In view of the case of individual companies, some companies take up countermeasures to conflict with lean production after the earthquake. However, in the context of the supply chain, it can be said that inventory management is a more serious problem for companies located in the upstream and midstream.

Meanwhile, inventory in the shipbuilding industries were increasing until 2012. After that, there was a declining trend. This may be related to the situation in this industry. In other words, the volume of orders for newly built ships has fallen sharply since the Lehman Shock, and is trending downward after peaking in 2011, when ships ordered before the Lehman Shock were completed. Global shipbuilding supply capacity tends to be excessive, causing market conditions to deteriorate. It is speculated that this industry-specific background had an effect on inventory reduction. 
In the communications equipment industry, there was a consistently decreasing trend. No common economic trends were found in this industry. In this study, we focused on the industry with increasing inventories, but we have not fully examined the factors. We will also focus on the industries that showed the opposite trend and examine the factors.

\section{CONCLUSION}

Until 2000, the risk of inventory minimization accompanying lean production was very much in focus. However, large-scale and long-term shutdowns were not taken into consideration, sufficiently.

Although discussions on low-level safety stocks have been undertaken in recent years, opinions on increasing or decreasing inventory varies among researchers. Questionnaires and interview surveys have revealed that there were a certain number of companies that increased inventory more than before the earthquake.

As a result of the analysis of the average age of inventory, it is clear that inventory is increasing in several industries. In particular, the food industry, which had been pointed out in previous studies, showed an increasing trend in multiple industry groups even in a small classification. It may be changed in practice from the conventional idea that inventory should be reduced as much as possible.

Preparations for crises are often wasteful in normal times. In other words, it costs a lot for storage and procurement. It may be thought that they are trying to reduce the total cost at the time of a disaster, keeping in mind the long-term business continuity. As a task for future research, it will be necessary to investigate the circumstances underlying the decision-making process of companies that have added to their inventory.

\section{ACKNOWLEDGMENT}

This work was supported by JSPS KAKENHI Grant Number 16K17220. 


\section{REFERENCES}

\section{English Literature}

Baroud, H., Francis, R., \& Barker, K. (2016). Data-driven methods for the risk analysis of global supply chains. In 13th International Conference on Probabilistic Safety Assessment and Management (PSAM 13).

Christopher, M., \& Lee, H. (2004). Mitigating supply chain risk through improved confidence. International Journal of Physical Distribution and Logistics Management, 34(5), 388-396.

Darwish, M. A., \& Goyal, S. K. (2011). Vendor-managed inventory model for single-vendor single-buyer supply chain. International Journal of Logistics Systems and Management, 8(3), 313-329.

Guan, R., \& Zhao, X. (2010). On contracts for VMI program with continuous review (r,Q) policy. European Journal of Operational Research, 207(2), 656-667.

Hara, S. (2016). A study of inventory level change before and after the Great East Japan earthquake: Implications for just-in-time in the 21st century. Asia-Pacific Management Accounting Journal, 11(2), 169-192.

Kleindorfer, P. R., \& Saad, G. H. (2005). Managing disruption risks in supply chains. Production and Operations Management, 14(1), 53-68.

Lee, H. L, Padmanabhan, V., \& Whang, S. (1997). Information distortion in a supply chain: The bullwhip effect. Management Science, 43(4), 546-558.

Lee, H. L, Padmanabhan, V., \& Whang, S. (2004). Information distortion in a supply chain: The bullwhip effect. Management Science, 50(12), 1887-1893.

Lee, J. Y., Cho, R. K., \& Paik, S. K. (2016). Supply chain coordination in vendor managed inventory systems with stockout-cost sharing under limited storage capacity. European Journal of Operational Research, 248(1), 95-106. 
MacKenzie, C. A., Santos, J. R., \& Barker, K. (2012). Measuring changes in international production from a disruption: Case study of the Japan earthquake and tsunami. International Journal of Production Economics, 138(2), 293-302.

Matsuo, H. (2015). Implications of the Tohoku earthquake for Toyota's coordination mechanism: Supply chain disruption of automotive semiconductors. International Journal of Production Economics, 161, 217-227.

Monden Y. (2011). Toyota production system: An integrated approach to just-in-time ( $4^{\text {th }}$ ed.). Boca Raton, FL: Productivity Press.

Nagarajan, M., \& Rajagopalan, S. (2008). Contracting under vendor managed inventory systems using holding cost subsidies. Production and Operations Management, 17(2), 200-210.

Nakamoto, M. (2007). Quake upsets lean supply model. Financial Times, July 23, 2007.

Park, Y., Hong, P., \& Roh, J. J. (2012). Supply chain lessons from the catastrophic natural disaster in Japan. Business Horizons, 56, 75-85.

Ono K., Akakura, Y., Kanda, M., \& Ishihara, M. (2015a). Analyzing and simulating supply chain disruptions to the automobile industry based on experiences of the Great East Japan Earthquake. Journal of Integrated Disaster Risk Management, 5(2), 42-69.

Simchi-Levi, D., Kaminsky, P., \& Simchi-Levi, E. (2000). Designing and managing the supply chain: Concepts, strategies, and case studies. New York: McGraw-Hill.

Waters, D. (2007). Supply chain risk management: Vulnerability and resilience in logistics. London, UK: Kogan Page Limited.

\section{Japanese Literature}

Akikawa, T. (2017). Disaster business continuity if food manufacturers: A supply chain perspective. Journal of Japan Logistics Society, 25, 23-30. 
Development Bank of Japan. (2017). Handbook of Industrial Financial Data 2017, Japan Economic Research Institute Inc.

Fujimoto, T. (2011). Supply chain competitiveness and robustness: A lesson from the 2011 Tohoku Earthquake and "virtual dualization". Manufacturing Management Research Center Discussion Paper Series, No.354.

Fujimoto, T. (2012). Virtual dualization of supply chains: Dealing with tradeoff between competitiveness and robustness. Organizational Science, 45(4), 25-35.

Kawakami, Y. (2000). International transfer of production system. Zeimu Keiri Kyokai Co. Ltd.

Kawano, M. (2012). Management accounting: Natural disasters and corporate risk management: Is the review of inventory control unnecessary?. Keiri-Kenkyu, 55, 281-292.

Okazaki, M. (2016). Management control to overcome crisis: Reconstruction example of the Great East Japan Earthquake. Chuokeizai-Sha Holdings, Inc.

Ono K., Akakura, Y., \& Kanda, M. (2015b). Analyzing impact of the east Japan great earthquake on the supply chain of the automobile industry. Journal of Japan Logistics Society, 23, 127-134.

Osada, T., \& Yano, Y. (2014). A study on disaster response on logistics of private companies are based on the questionnaire survey. Journal of Japan Logistics Society, 22, 259-266.

Oura, K. (2015). Organizational design for adapting supply chain risk: A case study of OMRON Corporation. The Journal of Cost Accounting Research, 39(2), 55-67.

Sasaki, I. (2012). Management accounting as crisis management research, In S. Hatta (Eds.), Do not weather the earthquake: Recommendations from accounting researchers (41-58). Tokyo: Dobunkan Shuppan Co. Ltd. 